\title{
A two-year survey on the effect of temperature changes on the incidence of myocardial infarction in patients referred to the Ali-ibn Abi Talib Hospital, Rafsanjan, Iran, in 2013-2014
}

\author{
Esmaeili Nadimi A, MD ${ }^{1 *}$, Hasani M, $\mathrm{MD}^{2}$, Allah-Tavakoli M, $\mathrm{PhD}^{3}$, Hakimizadeh E, MSc ${ }^{4}$, Bakhshi $\mathrm{H}$, \\ $\mathrm{MSc}^{5}$ \\ 1- Associate Prof., Dept. of Cardiology, School of Medicine, Rafsanjan University of Medical Sciences, Rafsanjan, Iran. \\ 2-General Physician, Rafsanjan University of Medical Sciences, Rafsanjan, Iran.3- Associate Prof., Dept of. Physiology, \\ Physiology -Pharmacology Research Center, Rafsanjan University of Medical Sciences, Rafsanjan, Iran.4- PhD Student of \\ Physiology, Physiology-Pharmacology Research Center, Rafsanjan University of Medical Sciences, Rafsanjan, Iran.5. PhD \\ Student, Molecular-Medicine Research Center, Rafsanjan University of Medical Sciences, Rafsanjan, Iran
}

Abstract

Received: August 2015, Accepted: December 2015

Background: The role of temperature changes, as an environmental risk factor, in the human health status has been investigated in recent studies. Accordingly, the present two-year study was conducted to evaluate the incidence of myocardial infarction (MI) in warm and cold seasons in Ali-ibn Abi Talib Hospital, Rafsanjan, Iran.

Materials and Methods: In this descriptive and cross-sectional study, 264 patients hospitalized with MI during a two-year period (2013-2014) were included. Data on the participants were obtained from their electronic medical files and on the weather from the official Rafsanjan Weather Bureau station. The collected data was then analyzed using statistical tests including chi-squared test, Fisher's exact test, and logistic regression model in SPSS software.

Results: Data showed that $41.80 \%$ of MI occurred in hot weather, $14 \%$ in cold, and the remaining $37.12 \%$ in mild weather. According to the type of MI, $49.47 \%$ of non-ST elevation myocardial infarction (NSTEMI) and $44.44 \%$ of ST-segment elevation myocardial infarction (STEMI) occurred in very hot weather while $13.54 \%$ of NSTEMI and $18 \%$ of STEMI occurred in very cold weather. This difference was not significant.

Conclusions: Based on our data, MI had occurred mostly in hot weather and more than half of the cases were NSTEMI.

Keywords: Temperature, Heart Attack, Myocardial Infarction

\section{Introduction}

In recent years, new geological models have been improved to determine the impact of climate changes on human health, especially in regions that experience heat waves. Most of the studies have been conducted in the Northern Hemisphere and have focused on death. Countries in the Southern Hemisphere have received less attention in this regard.
Determination of the socioeconomic risk factors that are potentially associated with mortality due to heat waves is required for the development or improvement of community health (1). The harmful effects of high and low temperature on cardiovascular diseases (CVDs) are clear. The

\footnotetext{
* Corresponding author: Ali Esmaeili Nadimi, Dept. of Cardiology, School of Medicine, Rafsanjan University of Medical Sciences, Rafsanjan, Iran.

Email: dr_esmaeili_n@yahoo.com
} 
known risk factors for CVD include smoking, excessive drinking of alcohol, poor diet, insufficient physical activity, high blood pressure and cholesterol, obesity and diabetes mellitus (DM). However, along with these risk factors, other factors such as temperature changes and air pollution also play a role in the incidence of CVDs. Changes in serum cholesterol levels and autonomic nervous system response has caused an increase in CVD events during temperature crises and this issue has become a concern among older people with heart problems (2).

According to some studies, increase in heart diseases varies in different seasons and in hot seasons it is higher than other seasons $(3,4)$. However, in most studies, the season that was associated with the highest rate of acute myocardial infarction (MI) was winter. With warming of the climate system, people develop tachycardia, cardiac contractility becomes low, but cardiac output per minute does not change $(5,6,7)$.

Moreover, low temperature causes an increase in the heart's need for oxygen, vasoconstriction, high blood pressure, and blood platelet activation, which increases the risk of arteryblocking plaque formation in the heart and MI (8). As mentioned above, the harmful effects of hot and cold weather are associated with mortality due to CVD (9).

Previous studies have shown that in addition to MI, cerebrovascular accident (CVA), pulmonary embolism, and aortic dissection are also likely to be affected by climate changes during the year (10). The main causes of death in Iran are MI and cardiovascular problems (11). Temperature changes can also cause an increase or decrease in the death rate due to climate changes (9). Therefore, this study aimed to investigate the incidence of MI during periods of very low and high temperatures over a period of two years from 2013 to 2014 in Ali-ibn Abi Talib Hospital of Rafsanjan, Iran.

\section{Material and Methods}

This was a cross-sectional study conducted on patients admitted with MI to Ali-ibn Abi Talib Hospital in Rafsanjan from the beginning of 2013 until the end of 2014. The study population consisted of all patients with MI admitted and archived using electronic medical records. The number of admissions due to MI at Ali-ibn Abi Talib Hospital during the two years was 264.

Data regarding the type of MI and the risk factors of MI (age, gender, and smoking) were gathered from the patient records using checklists. The mentioned records were based on the codes of MI types. Data regarding temperature consisted of the average daily temperature of Rafsanjan and were obtained from the Meteorological Organization of Kerman Province, Iran. Based on meteorological indices, temperatures of $8{ }^{\circ} \mathrm{C}$ and lower were classification as very low, temperatures greater than $20{ }^{\circ} \mathrm{C}$ as very high, and temperatures between $8-20{ }^{\circ} \mathrm{C}$ as moderate temperatures (12). After entering the data in SPSS software (version 18, SPSS Inc., Chicago, IL, USA), they were compared using descriptive statistics (frequency, percentage, and mean), analytical methods (chi-square), and logistic regression. These data included the specified items in the checklist, including MI type and MI risk factors (age, gender, and smoking) which were used as variables in this study. Another important data was the temperature status of each day, which was recorded in the software as the average temperature of Rafsanjan. In addition to daily comparisons, monthly and seasonal comparisons were also conducted.

\section{Results}

The mean and standard deviation of age of the participants was $61.7 \pm 13.96$ years (men: 59.37 \pm 13.90 years, women: $65.21 \pm 13.30$ years). Among the participants, 187 (70.8\%) were men and $77(29.2 \%)$ were women. The age range of 
men was 27 to 92 years and the age range of women was 35 to 90 years. Moreover, 75 (28.4\%) participants were smokers and $71.6 \%$ were not. Smokers smoked an average of 11.6 cigarettes per day and these individuals had smoked for an average of 2.89 years. These values were different among men and women. Data showed that 68 (36.4\%) men were smokers and they smoked an average of 10.59 cigarettes per day, and had been smoking for an average of 10 years. However, 7 women smoked an average of 21.43 cigarettes per day.

Table 1: distribution of variables based on myocardial infarction type

\begin{tabular}{cccccc}
\hline \multicolumn{2}{c}{ variables } & NSTEMI/N & STEMI & Total & \multirow{2}{*}{ P-value } \\
\hline \multirow{2}{*}{ Gender } & Man & $72.2 / 135$ & $27.8 / 52$ & $100.0 / 187$ & \multirow{2}{*}{0.761} \\
\cline { 2 - 5 } & Woman & $74.0 / 57$ & $26.0 / 20$ & $100 / 77$ & \\
\hline \multirow{2}{*}{ smoking } & Yes & $69.3 / 52$ & $30.7 / 23$ & $100 / 75$ & \multirow{2}{*}{0.435} \\
\cline { 2 - 5 } $\begin{array}{c}\text { Treatment } \\
\text { Outcome }\end{array}$ & No & $74.1 / 140$ & $25.9 / 49$ & $100 / 189$ & \\
\cline { 2 - 5 } & Discharged & $76.0 / 187$ & $24.0 / 59$ & $100 / 246$ & \multirow{2}{*}{0.001} \\
\hline
\end{tabular}

* The used statistical tests were chi-square and Fisher's exact test and significance level was 0.05

The distribution of patients by type of MI showed that $135(72.2 \%)$ men and $57(74 \%)$ women had non-ST elevation myocardial infarction (NSTEMI) and the rest had STsegment elevation myocardial infarction (STEMI) $(\mathrm{P}=0.7)$. According to smoking status of patients, results showed that $69.3 \%$ and $30.7 \%$ of smokers had NSTEMI and STEMI, respectively. However, $74.1 \%$ and $25.9 \%$ of non-smokers had NSTEMI and STEMI, respectively. This difference was not statistically significant $(\mathrm{P}=0.435)$. Recovery was observed in $76 \%$ of the discharged patients with NSTEMI and $24 \%$ of the discharged patients with STEMI. Deaths were reported in $27.8 \%$ of patients with NSTEMI diagnosis and in $72.2 \%$ of patients with STEMI, and this difference was statistically significant $(\mathrm{P}<0.001)$ (Table 1$)$.

Table 2: The relationship between the risk of myocardial infarction and temperatures in the logistic regression model

\begin{tabular}{|c|c|c|c|c|c|c|c|}
\hline \multirow{2}{*}{ Variables } & \multirow{2}{*}{$\mathbf{B}$} & \multirow{2}{*}{ S.E } & \multirow{2}{*}{ Wald } & \multirow{2}{*}{ Sig } & \multirow{2}{*}{$\operatorname{Exp}(B)$} & \multicolumn{2}{|c|}{ 95\% C.I.for $\operatorname{EXP}(B)$} \\
\hline & & & & & & Lower & Upper \\
\hline Gender & 0.209 & 0.359 & 0.34 & 0.56 & 1.2 & & \\
\hline Age & 0.009 & 0.011 & 0.702 & 0.4 & 1.009 & & \\
\hline Job & 6.662 & 0.0013 & 0.000 & 1 & 0 & & \\
\hline disease & 0.000 & 0.001 & 0.291 & 0.59 & 1 & 0.99 & 1.001 \\
\hline smoking & 0.447 & 0.369 & 1.463 & 0.22 & 1.5 & 0.75 & 3.22 \\
\hline $\begin{array}{ll}\text { amount } & \text { of } \\
\text { smoking } & \end{array}$ & 0.017 & 0.017 & 0.993 & 0.31 & 1.01 & 0.98 & 1.05 \\
\hline $\begin{array}{l}\text { duration of } \\
\text { smoking }\end{array}$ & -.0 .031 & 0.025 & 1.493 & 0.22 & 0.97 & 0.92 & 1.019 \\
\hline
\end{tabular}


The results of the incidence of MI divided by year and season showed that maximum and minimum number of cases of MI had occurred during winter and fall of 2013 and 2014, respectively. Nevertheless, this difference was not statistically significant $(\mathrm{P}=0.527$ and $\mathrm{P}=$ 0.296, respectively). In this study, logistic regression was used to determine climate changes by considering risk factors such as age, gender, occupation, disease, and the amount and duration of smoking and the results were not statistically significant (Table 2).
The final finding of the present study was related to the prevalence of MI in cold (average annual temperature of lower than $\left.8{ }^{\circ} \mathrm{C}\right)$, moderate (average annual temperature between 8-20 ${ }^{\circ} \mathrm{C}$ ), and warm temperatures (average annual temperature of higher than $20^{\circ} \mathrm{C}$ ). The results showed a reduction of the percentage of NSTEMI incidence with the decreasing of temperature. However, the percentage of STEMI incidence had increased. Overall, the statistical test showed no significant difference $(\mathrm{P}=0.600)$ (Table 3).

Table 3: Distribution of myocardial infarction with regards to high, moderate, and low temperature Discussion

\begin{tabular}{cccccc}
\hline \multirow{2}{*}{ Variables } & \multicolumn{3}{c}{ Temperature Rang } \\
\cline { 2 - 5 } & & $\begin{array}{c}\text { high } \\
\text { temperature } \\
\mathbf{2 0}^{\mathbf{0}}\end{array}$ & $\begin{array}{c}\text { moderate } \\
\text { temperature } \\
\mathbf{8}^{\mathbf{0}} \mathbf{- 2 0}^{\mathbf{0}}\end{array}$ & $\begin{array}{c}\text { low } \\
\text { temperature } \\
<\mathbf{8}^{\mathbf{0}}\end{array}$ & \multirow{2}{*}{ P-Value } \\
\hline \multirow{2}{*}{$\begin{array}{c}\text { myocardial } \\
\text { infarction }\end{array}$} & NSTEMI & $74 / 8 \%(\mathrm{n}=95)$ & $72 / 4 \%(\mathrm{n}=71)$ & $66 / 7 \%(\mathrm{n}=26)$ & \\
\cline { 2 - 5 } & STEMI & $25 / 2 \%(\mathrm{n}=32)$ & $27 / 6 \%(\mathrm{n}=27)$ & $33 / 3 \%(\mathrm{n}=13)$ & \multirow{2}{*}{0.630} \\
\cline { 2 - 5 } & Total & $100 \%(\mathrm{n}=127)$ & $100 \%(\mathrm{n}=98)$ & $100 \%(\mathrm{n}=39)$ & \\
\hline
\end{tabular}

\section{Discussion}

The harmful effects of climate changes could increase the burden of diseases affecting public health (13-16). The World Health Organization (WHO) has estimated more than 150,000 deaths per year due to the impact of these changes in the last 3 decades (17). This increase in disease ). The variations in the burden of major diseases such as CVDs are the result of climate change. This has been reported by many studies in different countries $(9,19,20)$. However, different countries have different climates; therefore, the reported results were different and the studies were not homogeneous (21).

The results of this study showed that there was no correlation between temperature and the incidence of MI. This relationship was also not significant regarding the division of subjects based on gender. A study was conducted in 2011 in Copenhagen, Denmark, with the aim of burden will encompass all spectrums of noncommunicable and communicable diseases. This will certainly include CVDs and respiratory diseases that are the leading causes of illness and death in most countries. Changes in global temperature and its effects on public health have recently attracted much attention (18 reviewing hospital admissions data (21). It was observed that temperature was inversely related to hospitalization due to CVDs, meaning that the increase in temperature significantly reduced the rate of hospitalization (21). Another study conducted in Shanghai, China, obtained similar results (22). However, the results of a study conducted in the UK in 2012 were inconsistent with the results of the abovementioned studies (23). In this study, it was shown that with increase in temperature, hospitalization due to acute MI was significantly increased. In other words, there was is a direct relationship between 
temperature and the number of hospitalizations (23). This heterogeneity in the results may be due to individuals' adaptation to the environment in each particular area (24).

By reviewing studies on the relationship between ambient temperature and hospitalization for CVD, it was found that the results reported for different research designs, countries, and cities were not homogeneous. This difference might be due to the fact that people in different areas have different tolerance levels and their bodies have adapted to the certain conditions of their living area (24). This particular adaption of the residents of different climates causes different responses towards temperatures above the thresholds of hot and cold temperatures. These reasons can be the cause of differences in the effects of weather variables on the people of the regions studied in this research.

The mechanism through which cold temperature causes an increase in the risk of CVDs is still not clear (25). However, several risk factors such as increased plasma cholesterol, fibrinogen, blood pressure, and white and red blood cell count can partly explain this mechanism (21). The main mechanism of the adverse effects of high temperatures may be the directing of blood by the blood circulatory system of the human body from the vital organs towards layers under the skin in order to regulate body temperature in high temperatures (26).

This study also showed that the prevalence of MI varies between seasons. Although this difference was not statistically significant, it was consistent with the results of other studies that have shown that lower temperatures increased the rate of CVD. The results of a study conducted in Denmark showed that temperature was inversely related to hospitalization due to CVD (21). Therefore, an increase in temperature significantly reduced cases of CVD, and thus, hospitalization for CVD. A study conducted in
Shanghai, China, also obtained the same results (27).

\section{Conclusion}

In this study, despite the apparent differences in the frequency and occurrence of MI, these differences were not statistically significant. One significant difference was the increase in the frequency of MI occurrence at lower temperatures which was also reported in other studies. The reviewing of studies on the relationship between environmental temperature and MI showed that the reported results in different studies designs, countries, and cities were not homogeneous. This matter requires broader researches and studies among different regions or countries. Moreover, a comprehensive review of a wider range of aspects of geographical areas and countries is necessary.

\section{Acknowledgments}

This article was extracted from a $\mathrm{PhD}$ thesis from Rafsanjan University of Medical Sciences. Our sincere appreciation goes to the participants of this research.

\section{Conflict of interest: None declared}

\section{Refrences}

1. Loughnan ME, Nicholls N, Tapper NJ. The effects of summer temperature, age and socioeconomic circumstance on Acute Myocardial Infarction admissions in Melbourne, Australia. Int $\mathrm{J}$ Health Geogr 2010; 9(1):41.

2. Huang C, Barnett AG, Wang X, Tong S. Effects of extreme temperatures on years of life lost for cardiovascular deaths: a time series study in Brisbane, Australia. Circ Cardiovasc Qual Outcomes 2012; 5(5):609-14.

3. Huang C, Barnett AG, Wang X, Tong S. Effects of extreme temperatures on years of life lost for cardiovascular deaths: a time series study in Brisbane, Australia. Circ Cardiovasc Qual Outcomes 2012; 5(5):609-14. 
4. Green RS, Basu R, Malig B, Broadwin R, Kim JJ, Ostro B. The effect of temperature on hospital admissions in nine California counties. Int J Public Health 2010; 55(2):113-21.

5. Bhaskaran K, Hajat S, Haines A, Herrett E, Wilkinson P, Smeeth L. The effects of ambient temperature on the incidence of myocardial infarction. Heart 2009; 95:1760-69.

6. Loughnan ME, Nicholls N, Tapper NJ. Demographic, seasonal, and spatial differences in acute myocardial infarction admissions to hospital in Melbourne Australia. Int J Health Geogr 2008; $7: 42$.

7. Liang WM, Liu WP, Chou SY, Kuo HW. Ambient temperature and emergency room admissions for acute coronary syndrome in Taiwan. Int $\mathbf{J}$ Biometeorol 2008; 52(3):223-9 .

8. Loughnan ME, Nicholls N, Tapper N. When the heat is on: Threshold temperatures for AMI admissions to hospital in Melbourne Australia. Appl Geogr 2010; 30(1):63-9 .

9. Bhaskaran $\mathrm{K}$, Hajat $\mathrm{S}$, Haines $\mathrm{A}$, Herrett $\mathrm{E}$, Wilkinson P, Smeeth L. Short term effects of temperature on risk of myocardial infarction in England and Wales: time series regression analysis of the Myocardial Ischaemia National Audit Project (MINAP) registry. BMJ 2010; 34:c3823. doi: http://dx.doi.org/10.1136/bmj.c3823

10. Swampillai J, Wijesinghe N, Sebastian C, Devlin GP. Seasonal variations in hospital admissions for ST-Elevation myocardial infarction in New Zealand. Cardiol Res 2012; 5(5):205-8 .

11. Mohammadian-Hafshejani A, Sarrafzadegan N, Hosseini S, Baradaran HR, Roohafza H, Sadeghi $M$, et al. Seasonal pattern in admissions and mortality from acute myocardial infarction in elderly patients in Isfahan, Iran. ARYA Atheroscler 2014; 10(1):46-54 .

12. Kalkstein LS, Valimont KM. Climate effects on human health. In: potential effects of future climate changes on forests and vegetation, agriculture, water resourses, and human health. Washington, D.C, U.S: Environmental Protection Agency, EPA Science \& Advisory Committee Monograph; 1987. P.122-52. Report No.25389.

13. Basu R, Samet JM. Relation between elevated ambient temperature and mortality: a review of the epidemiologic evidence. Epidemiol Rev 2002; 24(2):190-202.

14. Kendrovski VT. The impact of ambient temperature on mortality among the urban population in Skopje, Macedonia during the period 1996-2000. BMC Public Health 2006; 6(1):44. DOI: 10.1186/1471-
2458-6-44

15. Cheng $\mathrm{X}, \mathrm{Su} \mathrm{H}$. Effects of climatic temperature stress on cardiovascular diseases. Eur J Intern Med 2010; 21(3):164-7.

16. Ebi KL, Balbus J, Kinney PL, Lipp E, Mills D, O'Neill MS, et al. US funding is insufficient to address the human health impacts of and public health responses to climate variability and change. Environ Health Perspect 2009; 117(6):857-62.

17. Patz JA, Campbell-Lendrum D, Holloway T, Foley JA. Impact of regional climate change on human health. Nature 2005; 438(7066):310-7.

18. Costello A, Abbas M, Allen A, Ball S, Bell S, Bellamy R, et al. Managing the health effects of climate change: Lancet and University College London Institute for Global Health Commission. Lancet2009; 373(9676): 1693-733.

19. Turner LR, Barnett AG, Connell D, Tong S. Ambient temperature and cardiorespiratory morbidity: a Systematic review and meta-analysis. Epidemiology 2012; 23(4):594-606.

20. Zhang Y, Li L, Hua Y, Nunn JM, Dong F, Yanagisawa M, et al. Cardiac-specific knockout of ET(A) receptor mitigates low ambient temperatureinduced cardiac hypertrophy and contractile dysfunction. J Mol Cell Biol 2012; 4(2):97-107.

21. Wichmann J, Andersen Z, Ketzel M, Ellermann T, Loft S. Apparent temperature and cause-specific emergency hospital admissions in Greater Copenhagen, Denmark. PloS One 2011; 6(7):e22904. DOI: 10.1371/journal.pone.0022904

22. Ma W, Xu X, Peng L, Kan H. Impact of extreme temperature on hospital admission in Shanghai, China. Sci Total Environ 2011; 409(19):3634-7.

23. Bhaskaran K, Armstrong B, Hajat S, Haines A, Wilkinson $\mathrm{P}$, Smeeth L. Heat and risk of myocardial infarction: hourly level case-crossover analysis of MINAP database. BMJ 2012; 345:e8050. doi: http://dx.doi.org/10.1136/bmj.e8050

24. Liang WM, Liu WP, Chou SY, Kuo HW. Ambient temperature and emergency room admissions for acute coronary syndrome in Taiwan. Int $\mathbf{J}$ Biometeorol 2008; 52(3):223-9.

25. Mercer JB. Cold-an underrated risk factor for health. Environ Res 2003; 92(1):8-13.

26. Kovats RS, Hajat S. Heat stress and public health: a critical review. Annu Rev Public Health 2008; 29:41-55.

27. Ma W, Xu X, Peng L, Kan H. Impact of extreme temperature on hospital admission in Shanghai, China. Sci Total Environ 2011; 409(19):3634-7. 